equivalent whole body exposure of $200 \mathrm{rad}$. As the person probably received the radiation dose in small increments at high dose rates spread out over five years, this might not be the appropriate calibration curve to use but we have not yet investigated the effects of dose fractionation.

We also observed in the 500 cells 18 dicentrics lacking their associated fragments. However, because the calibration curves are based solely on dicentric yield in complete cells ${ }^{6}$ it is not possible to interpret them in terms of dose. The absence of the associated deletions suggests that mitosis may have occurred in vivo following irradiation. Such divisions are normally rare, but when they occur the fragments, which lack a centromere, pass wholly into one or other daughter cell. Bearing in mind that the average lifetime of mature lymphocytes may be several years, Bender ${ }^{7}$ states that the presence of cells lacking expected fragments may indicate that the chromosome damage has been sustained over a considerable period. This theory is in agreement with the present findings where the history of malpractice is known to span five years.

Studies of this nature, especially where there is a lack of reliable physical dosimetry data, illustrate the valuable contribution which chromosome analysis is making to good radiological protection practice. In addition, the accumulation of this type of data is necessary for the eventual evaluation of risk of the late effects of radiation in terms of acute biological effect.

We thank Mr C. D. Burgess of HM Factory Inspectorate and Miss E. J. Eltham for assistance.

$$
\begin{aligned}
& \text { D. C. Lloyd } \\
& \text { R. J. Purrott } \\
& \text { G. W. Dolphin }
\end{aligned}
$$

National Radiological Protection Board,

Harwell,

Didcot, Berkshire

Received July 13, 1972.

1 Dolphin, G. W., and Purrott, R. J., IAEA-SM-143/8, 611 (International Ätomic Energy Agency, Vienna, 1971).

2 Evans, H. J., in Human Population Cytogenetics (edit. by Jacobs, P. A., Price, W. H., and Law, P.), 192 (University Press, Edinburgh, 1970).

${ }^{3}$ UNSCEAR, Report of the United Nations Scientific Committee on the Effects of Atomic Radiation (General Assembly Official Records, 24th Session, Supplement No. 13 (A/7613), New York, 1969).

4 Norman, A., Sasaki, M. S., Ottoman, R. E., and Fingerhut, A. G., Blood, 27, 706 (1966).

5 Buckton, K. E., Smith, P. G., and Court-Brown, W. M., in Human Radiation Cytogenetics (edit. by Evans, H. J., CourtBrown, W. M., and McLean, A. S.), 106 (North Holland, Amsterdam, 1967).

6 Purrott, R. J., and Lloyd, D. C., NRPB(R)2 (National Radiological Protection Board, Harwell, 1972).

7 Bender, M. A., in Manual on Radiation Haematology, IAEA Technical Report No. 12.3 (International Atomic Energy Agency, Vienna, 1971).

\section{Neuromuscular Control of Trumpeters' Lips}

SCIENTIFIC experiments on musical performance are surprisingly sparse when one considers that neuromuscular control of skilful motor performance reaches its acme in music. A case in point is the embouchure of brass instrumentalists, that is, the control of the firmness and vibration of the lips in relationship to each other and to the mouthpiece. The pedagogical literature is in a "state of chaos" according to Weast". Among anatomists little more is known today about the normal function and kinesiology of the muscles of facial expression than has been known for a century -knowledge gained through the dissection of corpses and simple observation:. With the exception of buccinator muscle during normal function ${ }^{3.4}$ and labial muscles during speech $^{5,6}$, the facial muscles have been almost ignored by electromyographers. Thus, electromyography (EMG) offers to reveal the function of the facial muscles as it has for many other parts of the body ${ }^{7}$.

With both science and art as our motives, we studied the effects of register, intensity and subjects' proficiency on the electromyographic potentials of selected facial muscles during trumpet performance by eighteen players with a wide range of experience. We recorded from bipolar fine-wire electrodes ${ }^{7}$ in the orbicularis oris muscle in both the upper and lower lips, levator anguli oris and depressor anguli oris. Our eighteen volunteer trumpet players possess a wide range of proficiency; at the top are three concert artists and at the bottom, three high school students with limited experience. The subjects were rank-ordered according to numbers of years of private study, years played and age. All subjects were exposed to the same controlled environment, technique, instrumentation and procedures. After a set warm-up period, each subject played on cue a series of fifty-one test items for recording; these were chosen to demand a wide variety of trumpet techniques, including extremes of dynamic and pitch range. EMG activity was quantified using a four-integer system as follows: 0 , nil; 1, slight; 2, moderate; and 3, marked (maximum). When testing for differences between related scores, that is, when comparing two measures on the same subject, we used the Wilcoxon matched-pairs signed-ranks test. For comparisons between independent scores, that is, measurements made on two different groups of subjects, we used the Mann-Whitney U test, as recommended by Siegel ${ }^{8}$.

Both register and intensity positively affect the embouchure's muscle activity $(P<0.005)$, register having a greater effect than intensity $(P<0.005)$.

Advanced trumpeters have more activity in the muscles surrounding the lips than those in the lips $(P=0.025)$ in contrast to the reverse finding with less advanced trumpeters who show no difference. This negates the widely accepted "drawstring or tug-of-war" theory which proposes that the lip muscles are pitted against the other facial muscles in the correct embouchure formation. The beginners demonstrate more muscle activity in the upper lip than in the lower lip $(P<0.005)$. Although the lip muscles can be considered anatomically as a single unit (a sphincter muscle surrounding the oral orifice), functionally the lips must be considered as two separate muscles. While the data do not show that advanced trumpeters have less muscle activity in the upper lip than in the lower lip, advanced trumpeters do show a smaller ratio of upper lip to lower lip activity than beginners. This finding suggests that beginners should either concentrate more activity in the lower lip or less activity in the upper lip, or both; but the present data do not disclose which of these possibilities caused the difference between groups.

\section{JOHN V. BASMAJIAN} ELMER R. WhITE

Regional Rehabilitation Research and

Training Center,

Emory University,

Atlanta, Georgia 30322

Received October 2, 1972.

${ }^{1}$ Weast, R. D., Brass Performance, an Analytical Text of the Physical Processes, Problems, and Technique of Brass (McGinnis and Marx, New York, 1961).

2 Basmajian, J. V., Muscles Alive: their Functions Revealed by Electromyography, second ed. (Williams and Wilkins, Baltimore, 1967).

3 DeSousa, O. M., and Vitti, M., O Hospital, 68, 105 (1965).

4 Blanton, P. L., Biggs, N. L., and Perkins, R. C., J. Dent. Res., 49, 389 (1970).

5 Lubker, J. F., and Parris, P. J., J. Acoust. Soc. Amer., 47, 625 (1970).

6 Leanderson. R., Persson, A., and Öhman, S., Acta Otolaryng., 263, $89(1970)$.

7 Basmajian, J. V., Science, 176, 603 (1972).

8 Siegel, S., Nonparametric Statistics for the Behavioral Sciences (McGraw-Hill, New York, 1956). 